\title{
Research on exhaust air heat recovery mode of air conditioning system in different types of buildings
}

\author{
Chen Aoxue ${ }^{1, a}$ \\ ${ }^{1}$ School of Municipal \& Environmental Engineering,Jilin Jianzhu University,Changchun, P.R.China \\ achenaoxue2002@163.com
}

Keywords: industrial buildings; hospital buildings ;public buildings; energy consumption characteristics; exhaust air characteristics; exhaust heat recovery.

Abstract. The characteristics of energy consumption and exhaust air of different types of buildings is introduced. The advantages and disadvantages of various heat recovery methods are discussed. According to the characteristics of different types of buildings, the scheme of exhaust heat recovery is determined.

\section{Introduction}

According to the guidelines content of comprehensive work program of the national energy-saving emission reduction, it advocates conserving resources and protecting the environment, to improve energy efficiency and enhance the ecological environment as the proposal, to strengthen the building energy saving, promote the use of solar and shallow geothermal energy, air, industrial exhaust heat and other buildings can be used to solve the spare demand. As an effective measure of energy saving and emission reduction, exhaust heat recovery system has attracted more and more attention. For different types of buildings, energy consumption characteristics of different exhaust characteristics are not the same, the air conditioning system should be designed in the respective characteristics, the exhaust heat recovery form which must take the characteristic of the building into consideration. Energy saving optimization of air conditioning system for different types of buildings is great importance to the development of building energy efficiency.

\section{The characteristics of energy consumption and exhaust air of different types of buildings}

The characteristics of energy consumption and exhaust air of industrial buildings. An industrial building is a house that engages in industrial production and services directly for production. Therefore industrial buildings are very different from civil buildings in use requirements, industrial buildings generally require a large area and space, with large span and high height, shape coefficient, and because the requirements of lighting and ventilation, the window area is far greater than the civil building. According to the production quality and thermal environment requirements which meet the indoor personnel or specific machine equipment operation, environmental requirements remain in a certain temperature and humidity conditions, or explosion-proof, dust-proof, asepsis, cleanliness, anti radiation etc..

Because of the unique characteristics of industrial buildings, building energy consumption is different from other buildings. Energy consumption of industrial building is higher than of civil building. Energy consumption of industrial buildings includes ventilation and air conditioning, lighting and other parts, wherein the energy consumption of ventilation and air conditioning accounted for $60 \%-90 \%$.The production environment and the industrial process of different types of industrial buildings, the ventilation and air conditioning energy consumption proportion is different, the proportion of energy consumption of photoelectric plant, spraying workshop and knitting factory accounted for about $85 \%$, while the proportion of energy consumption in the assembly workshop about $63 \%$ [1]. Industrial buildings require the high control for environment, heating and air conditioning control mostly belongs to constant temperature and humidity system. Due to the special requirements of some industrial operation equipment, the air conditioning control system and indoor 
temperature and humidity and other environmental parameters on the high requirements of industrial buildings. The calorific value of the equipment, which transfers to indoor air and envelope by convection and radiation, it can form cooling load, increase the energy consumption of air conditioning.

Most of the industrial buildings will produce a lot of heat and humidity in the production process, part of process will produce large amounts of harmful substances, the exhaust air will carry aldehydes and ketenes, esters, alcohols, benzene, alkanes, $\mathrm{SO}_{2}, \mathrm{CO}_{2}, \mathrm{NO}_{\mathrm{X}}, \mathrm{CS}_{2}$ and dust particles and other substances, These substances have peculiar smell, and has carcinogenic effects, some ingredients can cause acid rain hazards and the greenhouse effect [1]. In order to ensure the normal operation of the equipment and the health of the staff, the new and exhaust air volume in the workshop is more than that of the general building. So the energy consumption of the new air will be great. Ventilation in industrial buildings are high temperature and high humidity state, with a lot of dust, formaldehyde, benzene and solid harmful substances. If the exhaust air directly discharged to the outdoor, it will severely pollute the surrounding environment, endangering people's health, it takes to inconvenience to the life of local residents and production.

The characteristics of energy consumption and exhaust air of hospital buildings. The hospital building is for medical and nursing care of patients with the use of public buildings, different from the ordinary civil buildings. Hospitals are usually divided into two categories: general hospitals with complete subjects and specialized hospitals for the treatment of certain diseases. The general hospital refers to the scale of construction in more than 500 beds, divided into medical, supply and management parts. Includes medical out-patient department, emergency department, inpatient department, medical department, security system, living facilities, office facilities. It is characterized by large scale construction, large investment, complete department, complicated function process and fast updating speed, which will inevitably lead to energy consumption increased greatly in hospital.

The hospital building has high environmental requirements, and the fresh air volume is about 2 times of that of the common office building. In the air conditioning system load, the fresh air load has the greatest impact on the energy consumption, which leads to great energy consumption in the heating, ventilation and air-conditioning systems. The United States heating refrigeration and Air Conditioning Engineers Association (ASHRAE) survey data show that the energy associated with the hospital air conditioning ventilation system accounts for about $67 \%$ of the total energy consumption of the hospital, the energy consumption of the fan and air conditioning ventilation and mixed energy consumption accounted for the annual energy consumption of 1/3[2]. The energy consumption of a typical hospital in Japan shows that the energy consumption associated with air conditioning accounts for $51.8 \%$ of the total energy consumption. China has also done a lot of research on the energy consumption of the hospital, air conditioning and heating energy consumption in a hospital in Shanghai accounted for $54 \%$ of the total energy consumption of air conditioning heating energy consumption [3]. Changsha hospital accounted for $63 \%$ of the total energy consumption of air conditioning [4], heating energy consumption in a hospital in Beijing accounted for $65 \%$ of the total energy consumption of air conditioning system. So ensure that air conditioning system for energy saving is important.

As a special place for patients to concentrate, the hospital has a large amount of bacteria in the air, mixing various odors and poor air quality. Therefore, the hospital air conditioning system should not only control the indoor temperature and humidity, but also need to control the cross infection within the hospital. So in order to ensure all the indoor air quality, maintain a reasonable pressure difference and air flow through the air, to prevent cross infection, will need to increase the quantity of fresh air and supply air, ensure the reasonable match of exhaust air and supply air. Therefore, it is possible to consider the application of exhaust heat recovery technology in hospital buildings.

The characteristics of energy consumption and exhaust air of public buildings. Large public buildings generally refer to buildings with a single body area of more than 20 thousand square meters and public buildings with central air conditioning. With the development of economy and society, the public the use function of the building is no longer a single, but more diverse and complicated, 
comprehensive public buildings, more types of city CBD integrated business district, shopping, office, hotel, apartments, clubs and leisure entertainment business complex etc.. Large public buildings have large construction scale, high volume ratio, high height, large mobility, complex function rooms, high integration, high efficiency and high density.

The remarkable characteristics of energy consumption of large public buildings are long running time, large heat dissipation and high energy consumption per unit area [5]. According to the function used in different areas of the building, the running time is not the same, the whole building energy consumption of the air conditioning is generally larger, to the air-conditioning system energy consumption as the main energy consumption, accounting for about half of the total energy consumption. Most of the buildings are enclosed space. In order to improve indoor air quality, this kind of building adopts large-scale air system, and the fan coil system has more energy consumption. Because of the high density and mobility of the shopping malls, there will be a great fluctuation in the number of people in different seasons and different days, resulting in a great difference in the peak value of the cold load between the air conditioners and the air conditioners. When the air conditioning design used heat flow density in maximum to calculate the cold load design, it will result in a large number of energy wastes.

\section{Characteristics of various exhaust heat recovery devices}

The principle of exhaust heat recovery is that the air is discharged from the air conditioning room, and the heat exchanger is used to heat the fresh air. The exhaust air after heat transfer is discharged in the form of exhaust gas. After pretreatment, the fresh air and the return air are mixed and then sent to the air supply point to the indoor air condition. When the heat collected in the exhaust air cannot handle the fresh air to the air supply point, the air is re treated with an auxiliary heating / cooling coil.

The heat recovery unit can be divided into sensible heat recovery unit and total heat recovery device according to the different energy recovery types. The commonly used heat recovery devices include rotary wheel, plate fin type, heat pipe type, solution cycle type and heat pump type.

Rotary heat recovery device is total heat recovery device, the advantages are high thermal efficiency, generally up to 70\%-90\%, Recyclable sensible heat, also the recovery of sensible heat and latent heat, with dehumidifying function. The equipment and operating cost is low, the equipment is compact. It has self-cleaning function, wind energy the system adapt to high temperature. The disadvantages are large volume, it occupies a larger space, and the wheel rotation need to consume some power, relatively large pressure loss. It is applicable to comfort air conditioning, industrial air conditioning, such as offices, shopping malls, hotels, hospitals, textile mills, etc., also applies to stadiums, swimming pools, kitchens and industrial air-conditioning.

Heat pipe heat exchanger is sensible heat recovery device. It has the advantages of compact structure, large heat transfer area per unit volume, and the safe and reliable operation, long service life. Each heat pipe from the heat exchanger system is easy replacement. Heat pipes are reversible, hot and cold fluids can change. The temperature difference between the hot and cold air flow is small, it can achieve certain recovery efficiency, the temperature drop is small, similar to the isothermal operation, it has high heat transfer efficiency, and the new exhaust will not cross contamination. Disadvantages are only recovery of sensible heat it cannot be recovered latent heat. It should be changed tilt direction when operating throughout the year. The utility model is suitable for the sensible heat recovery of high-temperature exhaust heat.

The plate fin type heat recovery unit has no transmission, and does not need power. It is a stationary heat recovery device. According to the requirements, different air filters are installed at the inlet of the fresh air and the exhaust air to prevent dust from blocking the passage, while maintaining certain cleanliness. Plate fin type full heat recovery device is suitable for general ventilation and air conditioning works. If the air contains poisonous, odorous and other harmful gases, it should not be adopted. The advantages of plate type total heat recovery device of the equipment is low cost, high recovery efficiency, compared to without intermediate heat medium and heat pipe, no temperature loss. 
The disadvantage is used for a long time, the air in the dirt accumulation, blocking channels in the channel. The heat recovery efficiency is lower than that of rotary heat recovery device. The plate fin sensible heat recovery device is only made up of different material of heat recovery unit, and the aluminum foil is used as the stroma. Plate fin sensible heat transfer can only recover sensible heat. Comfortable air conditioning (office buildings, hotels, department stores, etc.) for public buildings, and small air conditioners for vehicles, homes, etc.. Air temperature and humidity requirements are entered.

The solution circulation heat exchanger is sensible heat recovery device. It has the advantages of air exhaust and fresh air in the pipeline is completely avoided, so it won't happen cross contamination between the new air and exhaust air. It suits for requirements of high cleanliness places, such as hospitals, sterile animal laboratory, emissions of toxic and harmful gases of industrial plant etc. The operation is stable and reliable, it has long service life, low equipment cost, and convenient maintenance. Because of the heat recovery device is indirect heat transfer, through the circulating liquid contact with the exhaust air and air temperature, it has heat loss, and low efficiency, heat recovery efficiency of the device is usually lower than 60\%.The equipment cannot recovery latent heat. The equipment need circulating water pump, therefore, there is certain power consumption. The utility model is suitable for the harmful substances in the exhaust air or the special sanitation requirements of buildings and the air conditioning system cannot be arranged together with fresh air and exhaust air.

The heat pump type heat recovery device is a sensible heat recovery device with high energy saving efficiency. In practical use, the performance coefficient COP of the heat pump (the ratio of the heat input to the heat input of the heat pump) can reach 3 4. Equivalent to the heat pump heat energy consumption is equivalent to 3 4 times the thermal equivalent. Visible, for the same amount of heat, the heat pump saves electricity than the electric heater.

The characteristics of each heat exchanger heat recovery system, different forms of heat exchanger performance, efficiency and utilization, equipment level, maintenance difficulty is also different from the consideration of heat recovery efficiency, the energy recovery unit can select a wheel heat exchanger, a plate fin type full heat exchanger, a solution circulation heat exchanger and a heat pump heat exchanger. In the initial investment, the initial investment of the rotary heat exchanger, the solution circulation heat exchanger and the heat pump heat exchanger is relatively high. There is a risk of cross contamination between the rotary heat exchanger and the plate fin heat exchanger. In the demand of dust content, the plate fin heat exchanger and plate fin heat exchanger require a high level, and the minimum is the solution circulating heat exchanger.

\section{Selection of exhaust air heat recovery mode of air conditioning system in different types of buildings}

Considering the characteristics energy consumption and exhaust air in different types of building, exhaust air of industrial buildings has large dust, aldehyde, benzene and solid hazardous materials, it selected the heat recovery device with dust content lowly, so the solution circulation type heat exchanger is chosen. The hospital building should take the prevention of cross contamination as an important consideration, so the heat recovery device of the heat pipe, the heat pump heat exchanger or the liquid circulation heat recovery device should be selected for the exhaust heat recovery device of the hospital building. Large public buildings are mostly central air conditioning systems. The system has large air flow, and the heat exchanger is selected. Heat pump heat exchanger is selected.

\section{Conclusions}

The energy consumption characteristic of industrial buildings, hospitals and large public buildings and exhaust characteristics is studied, and comparison of the advantages and disadvantages several heat recovery modes, such as rotary plate fin type, heat pipe, the solution circulation type, heat pump and, find out suitable exhaust heat recovery scheme of building air conditioning system in different types of buildings 
1)Rotary heat recovery device has a great heat recovery efficiency, generally up to $70 \%-90 \%$.It can meet the high temperature of the exhaust system. Heat pipe heat exchanger is sensible heat recovery device, it has high heat exchange efficiency, the fresh air and exhaust air will not cross contamination. The utility model is suitable for the sensible heat recovery of high-temperature exhaust heat. Plate fin type full heat recovery device is suitable for general ventilation and air conditioning works. If air contains poisonous, odorous and other harmful gases, it should not be adopted. Plate fin heat recovery unit has higher recovery efficiency, in which plate fin sensible heat exchange can only recover sensible heat. Comfortable air conditioning (office buildings, hotels, department stores, etc.) for public buildings, and small air conditioners for vehicles, homes, etc.. Air temperature and humidity requirements are entered. The solution circulation type heat exchanger for heat recovery device type, does not occur, the new row of cross contamination between the wind, suitable for cleanliness requirements of high places, such as hospitals, sterile animal laboratory, emissions of toxic and harmful gas workshop; heat pump type heat exchanger for heat recovery type device, energy saving efficiency is efficient.

2) Industrial building exhaust contains harmful substances, should choose the solution circulation heat recovery. To prevent cross contamination, hospital building should choose the heat pipe type heat exchanger, the heat pump heat exchanger or liquid circulation heat recovery device. Large public buildings usually use the central air conditioning system, it exhaust heat recovery device should be select heat pump heat exchanger.

\section{Acknowledgements}

This work was financially supported by science and technology research projects of the Education Department of Jilin Province. Research on the recovery fresh air heat pump units in the air conditioning energy saving reform of existing public building in the serious cold regions, project Numbers: J20111031,thanks to technology and financial support of Education Department of Jilin Province

The project also has been supported by science and technology development project funding for ministry of housing and urban-rural development of the people/s republic of China. The manufacture of recovery fresh air heat pump unit suitable for severe regions. project Numbers: NO. 2010-k1-45, thanks to technology and financial support of ministry of housing and urban-rural development of the people/s republic of China.

\section{References}

[1] Wang Xinhua. Study on wind heat recovery scheme for industrial buildings [J]. Clean and air conditioning technology, 2013, 3 (1): 8-11.

[2] Tu Guangbei. Hospital building air conditioning purification and equipment [M]. China Construction Industry Press, 2005.

[3] Lu Bin. Analysis of energy usage and energy saving diagnosis of Shanghai hospital [J]. HVAC 2009,4: 61-64.

[4]Lin Ailin. Measurement and analysis of building energy consumption in Changsha hospital, [D], Hunan University, 2009. 